\title{
Highlighting Human Rights Violations: The Mock Tribunal on Abortion Rights in Kenya
}

\section{Sarah Onyango and Cynthia Mugo}

\begin{abstract}
1 Background
In Kenya, rates of unsafe abortions are very high and there is a growing national debate about the consequences and solutions. This article describes an attempt to foster dialogue among concerned citizens and healthcare providers through the approach of a mock tribunal before a panel of 'judges', with evidence from women who have undergone unsafe abortions.
\end{abstract}

\subsection{Magnitude of unsafe abortion}

Unsafe abortion is a major public health problem in Kenya and accounts for 30-50 per cent of maternal deaths (BBC Monitoring 2004). Kenya's maternal mortality ratio is $414 / 100,000$ live births (KDHS 2004).

Although accurate abortion data are limited because of restrictive laws, several studies have been conducted that give an indication of the magnitude of unsafe abortion and its consequences to the health of women, to the health sector and to the country. Approximately 300,000 spontaneous and induced abortions occur each year, putting the national incidence of abortion per 1,000 women aged $15-49$ years at 44.7. An estimated 20,000 women are treated in public hospitals annually with abortion-related complications. About 60 per cent of the beds in the gynaecological ward at Kenyatta National Hospital are estimated to be occupied by patients suffering from abortion complications (Lema and Kabeberi-Macharia 1992). Complications of unsafe abortion are the single biggest contributor to gynaecological emergencies (Gebreselassie et al. 2004). Approximately 800 unsafe abortions are performed every day with 2,600 women dying from unsafe abortions per year (Ministry of Health 2004a).

\subsection{Underlying factors}

Contraceptives and family planning: According to the Kenya Demographic and Health Survey 2003, only 39 per cent of all women surveyed were using some form of contraceptive (KDHS 2004). The unmet need for family planning is 24 per cent. The survey also showed that the steady increase of contraceptive use among married women since the 1980s had slowed considerably since 1998. Lack of information and access to contraceptives contribute to unwanted pregnancies and unsafe abortions.

Sexual and gender violence: In a 2003 survey of 1,652 Kenyan women aged 17-77, 52 per cent reported being sexually abused in their lifetime, while over 30 per cent of the surveyed women reported an experience of forced sexual intercourse in their lifetime (Johnston 2003). In spite of the high incidence of sexual violence, the law does not explicitly provide for access to abortion in the case of rape and incest, although the Ministry of Health's National Guidelines on the Medical Management of Rape and Sexual Violence state that pregnancy termination should be discussed with sexual violence survivors as an option in case conception occurs as a result of the rape (Ministry of Health 2004b). The widespread occurrence of rape coupled with inconsistent access to emergency contraception and the lack of access to safe abortion creates a situation that doubly victimises women and seriously imperils their health and lives.

\subsection{The abortion law in Kenya}

The law in Kenya restricts abortion to situations where the life of the woman is at risk.

Furthermore, such services can be offered 'in good 
faith' only by a qualified doctor registered by the Medical Practitioners and Dentists Board. The chief statute that governs the prohibition of abortion is the Penal Code (Cap 63 Laws of Kenya). The law criminalises the provider, the woman and the person who provides the abortificient, with all three liable for sentences of up to 15 years in prison if found guilty. The law is derived from the former British law that has long since been changed in Britain for a liberal law allowing broader access to safe abortion services. Although the law has been enforced in the past, very few cases are on record (Lema and Njau 1991), an indication that the system tacitly acknowledges the need for abortion services. Law enforcement agencies rarely seek out women or providers who have induced abortions, except for the relatively few cases that end up with serious complications or death of the woman; or when there are complaints from family members or members of the public.

These restrictive abortion laws are discriminatory, as only the poor are denied access to safe abortion services. Those who can afford to pay can have safe abortion services both within the country and in other countries where abortion is available. It is the poor women who are forced to have clandestine abortions, often in unsanitary conditions at the hands of untrained practitioners, greatly increasing the risk of abortion-related complications and even death. Adolescents are also less likely to be able to access and afford safe abortion services and may feel additional pressure to terminate a pregnancy unsafely because of the social stigma and the impossibility of continuing education. The law thus makes unsafe abortion not only a public health and human rights issue, but also an issue of social equity. Furthermore, with a low doctor:population ratio, many women who may need to have an abortion on grounds of risk to their health, may be denied this service if they do not have access to a medical doctor.

The Kenya experience therefore shows that legal reform is critical to addressing the high morbidity and mortality associated with unsafe abortion. Where countries have legalised abortion, morbidity and mortality declined significantly, as was the case in South Africa. Studies conducted in South Africa show a significant decline in abortion-related maternal morbidity and mortality since the Choice on Termination of Pregnancy Act was passed in 1996.

\subsection{Human rights perspective}

Kenya is signatory to various international human rights instruments which have set minimal standards for the promotion and protection of human rights, including sexual and reproductive health rights. These guarantee couples the right to decide freely and responsibly the number, spacing and timing of their children, the right to make decisions concerning reproduction free of discrimination, coercion and violence, the right to health and the right to self determination.

The denial of a pregnant woman's right to make an independent and non-coerced decision regarding abortion violates a wide range of human rights and poses a threat to a wide range of human rights. Three human rights specifically apply to the need for safe and legal abortion:

- Women's right to life and survival: the right to life is protected in multiple human rights instruments. Forcing a woman to undergo a clandestine abortion threatens her rights to life and survival, violating the most fundamental of human rights.

- Women's right to health: unsafe abortion can kill or maim women, and safe abortion care protects women's right to health. In the context of abortion, the right to health can be interpreted to require governments to take appropriate measures to ensure that women are not exposed to the risk and humiliation of unsafe abortions.

- Women's right to non-discrimination: the right to gender equality is a fundamental principal of human rights law. Denying women access to abortion is a form of gender discrimination because only women need and have abortions, and only women are exposed to risks that are not experienced by men when they are forced to resort to clandestine abortions.

In Kenya, our stance as members of the Reproductive Health and Rights Alliance (RHRA) is also that women have a right to reproductive self-determination: a woman has the right to make decisions regarding her own body. This includes protection of the right to physical integrity, the right to decide freely and responsibly the number and spacing of one's children, the right to privacy, etc. Governments and fundamentalist religious bodies should play no role in forcing women to have children they do not want and in denying them access to safe abortion and safe contraception. 


\section{Organisation of the tribunal}

In the context of these reproductive and health rights issues, the Mock Tribunal on Abortion Rights in Kenya was organised by the Reproductive Health and Rights Alliance (RHRA), under the leadership of its member organisation, the Kenya Human Rights Commission (KHRC).

\subsection{The Reproductive Health and Rights Alliance}

The Reproductive Health and Rights Alliance (RHRA) was formed in July 2004 by professional associations and non-governmental organisations (NGOs) working in Sexual and Reproductive Health (SRH) and rights, human rights and women's rights, as a response to the urgent need for a coordinated effort to address $\mathrm{SRH}$ and rights, particularly abortion rights, in Kenya. A primary founding objective of the RHRA is the need to raise public awareness on the magnitude and consequences of unsafe abortion, and of the need for safe abortion services in securing and ensuring women's SRH and rights, and contributing to a decrease in abortion-related maternal mortality and morbidity in Kenya. The RHRA is advocating for a legal, political and social environment that will ensure access to safe abortion services. Eleven professional organisations and NGOs are active members of the RHRA. The RHRA believes that:

- sexual and reproductive rights are human rights;

- every woman has a right to the highest attainable standard of health, to safe reproductive choices and to high-quality healthcare, including safe abortion services where needed;

- no woman should die from complications of unsafe abortion;

- the government has an obligation to save women's lives.

The RHRA uses several strategies to advocate for laws and policies that support access to safe abortion services. Specifically, the RHRA creates awareness among policymakers, opinion leaders, advocates and the public of the various conventions relating to $\mathrm{SRH}$ and rights, and seeks to garner and sustain support for policy and law review/reform. This is achieved through public debates and other public forums. The Mock Abortion Tribunal of 26 June 2007 was one such forum.

\subsection{The tribunal}

The tribunal was planned strategically to take place on 26 June - the 'International Day against Torture'.
The objective of the tribunal was to publicise the negative consequences of the criminalisation of abortion in Kenya. The tribunal also sought to inform the public and other stakeholders that restricting access to safe abortion services does not necessarily stop women from having abortions, but rather increases the risk associated with unsafe abortions.

The programme included testimonies from four women who have undergone unsafe abortion and from doctors and nurses, plenary discussion and reactions from four rights experts acting as 'judges'. They included three lawyers and human rights activists, one of whom was the chief judge and a practising, renowned obstetrician/gynaecologist. Through their testimonies, the four women shared their experiences, their pain and suffering and their reasons for seeking unsafe abortions in spite of the restrictive law - and gave a human face to the abortion issue in Kenya. Through the testimonies and 'judgement', the tribunal also aimed to highlight the magnitude of unsafe abortion; dispel myths and misconceptions about abortion; to speak out on the high morbidity and mortality resulting from complications of unsafe abortion, their negative effects on the health system and the economy of the country; and to enhance awareness of women's reproductive rights as human rights. The tribunal presented an opportune moment to bring the abortion debate to the fore and strengthen the dialogue on saving women's lives.

The tribunal was modelled on the ground-breaking Polish Tribunal of 2000 (Girard and Nowicka 2002) and other similar tribunals organised at international meetings or UN conferences, to document violations and provide a high-profile venue for women's voices to be heard and women's human rights to become more visible. Reference was also made to the Global Tribunal on Violations of Women's Human Rights held in 1993 at the UN World Conference on Human Rights in Vienna. This tribunal helped to galvanise political will to ensure that steps such as the appointment of a Special Rapporteur on Violence against Women and the adoption of the UN Declaration on the Elimination of Violence Against Women were taken.

The date of the tribunal was widely advertised through the media, through posters, pamphlets and emails. This resulted in a high demand for attendance, which the organisers had to greatly restrict because of the capacity of the venue. Unfortunately, this 
publicity also provoked the anti-choice groups, who publicly indicated that they would have the four testifiers arrested and charged with abortion-related offences. The planning committee for the tribunal responded by changing the plans and instead, audiotaped recordings of the testimonies of the four women were played at the tribunal.

The tribunal was held at a central location in Nairobi to allow easy access for members of the public and was well attended. Over 400 people participated, including the public, representatives of NGOs, human rights organisations and opposition groups, legal and health professionals and the media. The tribunal was officially opened by the Assistant Minister for Health, Dr Kibunguchy, who decried the high level of unsafe abortion in Kenya and the need to 'think outside the box', making reference to the urgent need to reform the current abortion law.

The testimonies of the four women presented at the tribunal were selected from 20 testimonies presented to a committee set up by the RHRA to collect stories of women who have experienced unsafe abortions. The women were selected through various RHRA contacts and the purpose of their testimonies explained. Those who consented were interviewed over several days to accurately document their story. The committee worked closely with individual testifiers to help them deal with the circumstances surrounding the abortion and to provide counselling and support. The committee consisted of a nurse, a sociologist and a human rights activist. All three had substantial knowledge of and experience in working on the issue and identified themes to guide the presentation of the testimonies at the tribunal. Because of the negative experiences many of these women had gone through, after counselling, those requiring further medical attention were referred to a health provider for care. The testimonies were written down to help the testifiers present their story consistently.

Through their testimonies, the women shared the factors that led them to seek the abortions; who performed the abortions; the personal and financial costs of the abortions; and the impact on their lives. Though not presented in person by the four women, the audio presentations still moved the audience who listened keenly. The presenters could be heard crying as they went through the grim details of their experiences.

\subsection{The testimonies}

The first testimony was from a 24-year-old woman living in the slums of Nairobi with a large family. She is the eldest in her family and having been orphaned following the death of her single mother, she is the sole breadwinner and provider for her four siblings. She had dropped out of school to care for her siblings. A single mother of one child, when she got pregnant five years ago, she decided that she could not afford to have another child. With the little funds she got from a cousin, she chose to go to an unqualified 'doctor' to have an abortion. At the time, she was seven months pregnant. Three years later, she got pregnant again, but had a miscarriage. She believes the miscarriage was a result of complications she may have developed from the unsafe abortion.

The second testifier was an 18-year-old woman, a school drop-out from a family of seven. Her parents are divorced and she lives with her father. She narrated her experiences with unsafe abortion. When she was 15 years old, she was raped by four men. She found out two months later that she was pregnant. She feared sharing her problem with her family, especially her father. As a Muslim woman, pregnancy outside of wedlock is not acceptable and she did not think her father would understand or support her. She opted to have an abortion, seeing this as her only choice under the circumstances. The only person she could share her tragedy with was her friend, who advised her to take very concentrated tea to induce the abortion because they had no money to seek the services of a health provider. She did have an abortion, but unfortunately developed complications - severe pain and bleeding, for which she had to seek medical help. At the health facility, she had her uterus evacuated and she finally recovered.

Although the first two testifiers opted to have abortions to end their unwanted pregnancies, the last two testifiers did not make the decision to have the abortion. Instead, this decision was made for them by others.

The third testimony was made by a friend of the woman, 'Sandra'. Sandra died when she was 14 years old from complications of unsafe abortion. Sandra's friend has never forgiven Sandra's mother 
for forcing Sandra to have an abortion, and so she wanted to share the story. When Sandra was six months pregnant, she was very sick and needed to seek medical attention. Up to that time, Sandra's mother did not know about the pregnancy, which Sandra had been able to conceal. On learning of Sandra's pregnancy, her mother immediately suggested she have an abortion. She could not imagine how she could face her community, and also worried that Sandra would not be able to complete her education. She took Sandra to a traditional birth attendant who, without Sandra's knowledge, induced the abortion. Unfortunately, Sandra developed severe complications, including bleeding and infection. She was taken to the health facility, but it was too late to save her life - she had lost a lot of blood and her uterus was damaged. Her mother was charged with murder, a charge that was later reduced to manslaughter and she was released on bail. However, she committed suicide shortly after, not being able to deal with the nightmare of losing her daughter. Sandra was never given a chance to make the decision as to whether or not to have the abortion.

Finally, the tribunal heard from a 32 -year-old mother of two boys aged 11 and 14 years. Her children are both handicapped - deaf and vision impaired. Although she wanted to have more children, her husband would not allow it, for fear that they would have further children with disabilities whom they could not support. When she got pregnant almost ten years ago, her husband would not hear of it. Being the sole breadwinner for the family, he forced her to have an abortion. This forced abortion traumatised her and in the end she separated from her husband.

The tribunal also heard from two health providers who shared their experiences in managing complications of unsafe abortion, describing unimaginable complications that women presented with following these abortions.

The Assistant Minister for Health, Dr Kibunguchy, gave a speech citing statistics on the magnitude and consequences of unsafe abortion, stressing the seriousness of the problem, the roles of unmet need for family planning and sexual violence, and highlighting the government's lack of clarity on the issue in laws and guidelines. He pointed out that the low doctor:population ratio means that many women are not even able to access legal abortion. He argued that abortion is not a black or white issue and that we need to 'think outside the box' in finding solutions. The solutions he recommended from the government were, however, within the box - focusing on prevention of unwanted pregnancy and improving provision of post-abortion care.

The participants were also allowed to comment and to present their views on the issue. During this session and throughout the hearing, pro-life activists tried to stop the tribunal, citing the need to protect the right of the unborn, but the workshop participants protested against this disruption, and insisted that the tribunal proceed. In the end, many of the disruptive individuals were thrown out of the venue. In spite of this, many eloquent points were made. One participant called the tribunal the first sober public discussion in Kenya on abortion. Proponents of the liberalisation of abortion law included nurses and gynaecologists who have had to deal with the consequences of unsafe abortion, and representatives from $\mathrm{SRH}$ and rights NGOs. The most commonly used arguments were based on public health concerns, explanations of the social, political and economic causes of unsafe abortion, and descriptions of the suffering caused by complications from unsafe abortion. Arguments included the culpability of government and society and the role of poverty, gender and income inequality in causing unwanted pregnancies and unsafe abortion. One person mentioned the Millennium Development Goals (MDGs). Some people argued that opposition to abortion is motivated by patriarchal interests.

Participants opposed to or concerned about any liberalisation of abortion law included gynaecologists, lawyers, representatives from Christian crisis pregnancy organisations and the Christian Medical Fellowship. Arguments included the concern that abortion damages women psychologically, and claims that prevention of unwanted pregnancies by information and family planning services is a better approach; abortion is the murder of children who have no voice, and abortion is against Christian and moral values. Two people claimed that even safe abortion can lead to health problems.

\subsection{The judgement}

In their response to the testimonies, the 'judges' addressed violations of human rights, women's rights, reproductive rights and the laws of Kenya 
involved in the prohibition of abortion. They also considered the international commitments that Kenya has made regarding these rights issues. The 'Chief Judge' responded to the other judges and was to have made a final judgement or verdict. However, because of the disruptions by anti-choice groups during the testimonies, the 'Chief Judge' preferred to defer the final judgement until a later date, to allow for this judgement to be given more publicity and support.

The judgement, which will shortly be presented, will reflect the diversity of issues affecting women's choices, including sexual violence and violence against women, socioeconomic circumstances, health and reproductive rights. It will highlight the ways in which the events recounted in the testimonies violate international human rights. It will also take into account specific policy or legal recommendations from the local and global level. In addition, the judgement will address more general indictments regarding the causes and consequences of violations of women's human rights and make recommendations and/or call for action from government aimed at eliminating the violations recorded in the testimonies. Finally, the judgement will outline steps that the testifiers, members of the public and other activists can take to end these human rights violations.

\section{Conclusions from the tribunal}

The tribunal proved to be an effective forum to engage in dialogue with the public and other stakeholders. Not only was the tribunal well attended, but it was widely covered in all the media - The Daily Nation, The Standard and on KTN television - and elevated the abortion debate to a fairly high level, as illustrated for example by the release of a press statement by Catholic Bishops. The media reporting was generally balanced, presenting both sides and including detailed statistics on the health consequences of unsafe abortion.
The tribunal also heard first-hand some of the factors that lead women in Kenya to seek unsafe abortions, including: socioeconomic reasons; the need especially for young girls to continue with their education; pregnancies arising from sexual violence, in particular rape; traditional and religious beliefs that for example do not tolerate women having children outside of marriage; social stigma; being too young; and fear of bearing children with severe abnormalities.

In conclusion, the tribunal contributed to generating a dialogue on the issue of abortion. For more than a week after the tribunal, the media presented facts and views from the public on the issue of abortion. Abortion was highlighted in all the key newspapers and on the radio and television stations. Both the reproductive rights groups and the anti-choice groups actively participated in the media dialogue.

The RHRA and other advocates now plan to take this dialogue further to build support for increased access to sexual and reproductive health services, including safe abortion services. As a follow-up to the tribunal, the RHRA will conduct a public function to disseminate the 'verdict'. In addition, testimonies of women who have had experiences with unsafe abortion will be published in a book for wider dissemination to the public and policymakers. The RHRA will continue to implement a wide range of activities. These will include conducting relevant research to support advocacy for change; further capacity building of RHRA members for advocacy; widely disseminating information on the magnitude and consequences of the problem through public and other forums, and on the obligations of Kenya to various regional and international conventions that support reproductive rights; and drafting policies in support of greater access to safe services. 


\section{Note}

* The authors would like to thank Joanna Crichton of the African Population and Health Research Center, Nairobi, Kenya for providing ideas and written inputs on the tribunal for this article.

\section{References}

BBC Monitoring International Reports (2004) Kenyan Medics Call for Legalization of Abortion to Reduce Maternal Deaths, 29 January

Gebreselassie, H.; Gallo, M.F;; Monyo, A. and Johnson, B. (2004) 'The Magnitude of Abortion Complications in Kenya', British Journal of Obstetrics and Gynaecology 112: 1229-35

Girard, F. and Nowicka, W. (2002) 'Clear and Compelling Evidence: The Polish Tribunal on Abortion Rights', Reproductive Health Matters 10.19: 22-30

Johnston, Tony (2003) The Sexual Abuse of Kenyan Women and Girls: A Briefing Book, Nairobi: Population Communication Africa

KDHS (2004) Kenya Demographic and Health Survey 2003, Calverton, MD: Central Bureau of Statistics (CBS); Ministry of Health (MOH) and ORC Macro
Lema, V.M. and Kabeberi-Macharia, J. (1992) A Review of Abortion in Kenya, Nairobi: Centre for the Study of Adolescence

Lema, V.M. and Njau, W.P. (1991) Abortion in Kenya: A Traditional Approach to Unwanted Pregnancy, Kenya: Centre for the Study of Adolescence Ministry of Health, Kenya (2004a) A National Assessment of the Magnitude and Consequences of Unsafe Abortion in Kenya, Kenya: Ministry of Health

Ministry of Health, Kenya (2004b) National Guidelines: Medical Management of Rape/Sexual Violence, Kenya: Division of Reproductive Health 